\title{
Potential effect of centre size on continuity of care and healthcare performance
}

\author{
Zhe Hui Hoo NIHR doctoral research fellow ${ }^{1}$, Rachael E Curley consultant in respiratory medicine \\ and adult cystic fibrosis ${ }^{2}$, Martin $\mathrm{J}$ Wildman consultant in respiratory medicine and adult cystic \\ fibrosis $^{2}$
}

'ScHARR, University of Sheffield, Room 1.03, Innovation Centre, Sheffield S1 4DP, UK; ${ }^{2}$ Sheffield Adult Cystic Fibrosis Centre, Brearley Outpatient, Northern General Hospital, Sheffield S5 7AU, UK

Barker and colleagues show that smaller practices have higher continuity of care, as measured by proportion of contact with the same doctor. ${ }^{1}$ Quality of the patient-doctor interaction is another aspect of continuity. Dunbar proposed that the number of meaningful stable relationships that can be maintained determines the optimum size of human groups. ${ }^{2}$ Practices managing a number of patients that is close to the Dunbar optimum may provide better quality interactions and thus achieve better outcomes. We urge the authors to evaluate the association between practice size and hospital admissions.

Secondary care studies that demonstrate better outcomes in larger hospitals typically assess acute surgical conditions, ${ }^{34}$ where procedural experience rather than quality of relationship is the main determinant of performance. Secondary care teams managing complex, long term conditions require not only a critical mass of expertise but also continuity and good relationships. The association between centre size and performance for these teams may be an inverted "U shape," meaning that a healthcare centre is most efficient at an optimum size, as predicted by Dunbar's number.

The challenge of maintaining continuity of care also exists in secondary care. Organising large practices into smaller teams may facilitate the pooling of resources while allowing healthcare professionals to work within the limits of Dunbar's number.
This strategy has been trialled in primary care ${ }^{56}$ and might also benefit secondary care teams managing complex long term conditions, with anecdotal data from Glasgow indicating improved care quality when the renal unit was split into four teams (R Mactier, personal communication, 2016).

\section{Competing interests: None declared.}

Full response at: http://www.bmj.com/content/356/bmj.j84/rr-10.

1 Barker I, Steventon A, Deeny SR. Association between continuity of care in general practice and hospital admissions for ambulatory care sensitive conditions: cross sectiona study of routinely collected, person level data. BMJ 2017;356:j84. doi:10.1136/bmj.j84 pmid: 28148478.

2 Zhou WX, Sornette D, Hill RA, Dunbar RIM. Discrete hierarchical organization of social group sizes. Proc Biol Sci 2005;356:439-44. doi:10.1098/rspb.2004.2970 pmid:15734699.

Hicks $\mathrm{CW}$, Wick EC, Canner JK, et al. Hospital-level factors associated with mortality after endovascular and open abdominal aortic aneurysm repair. JAMA Surg 2015;356:632-6. doi:10.1001/jamasurg.2014.3871 pmid:25970850.

4 Reames BN, Ghaferi AA, Birkmeyer JD, Dimick JB. Hospital volume and operative mortality in the modern era. Ann Surg 2014;356:244-51. doi:10.1097/SLA.0000000000000375 pmid: 24368634.

5 Butler M, Kim H, Sansone R. Improved continuity of care in a resident clinic. Clin Teach 2017:356:45-8. doi:10.1111/tct.12489 pmid:26748569.

Risi L, Bhatti N, Cockman P, et al. Micro-teams for better continuity in Tower Hamlets: we have a problem but we're working on a promising solution!Br J Gen Pract 2015;356:536 doi:10.3399/bjgp15X687025 pmid:26412823.

Published by the BMJ Publishing Group Limited. For permission to use (where not already granted under a licence) please go to http://group.bmj.com/group/rights-licensing/ permissions 